\title{
Multilayer graphane synthesized under high hydrogen pressure
}

V.E. Antonov ${ }^{\text {a, } * \text {, I.O. Bashkin }}{ }^{\text {a }, \text { A.V. Bazhenov }}{ }^{\text {a }}$, B.M. Bulychev ${ }^{\text {b }}$, V.K. Fedotov ${ }^{\text {a }}$, T.N. Fursova $^{\text {a }, \text { A.I. Kolesnikov }}{ }^{\text {c }, ~ V . I . ~ K u l a k o v ~}{ }^{\text {a }}$, R.V. Lukashev ${ }^{\text {d, D.V. Matveev }}{ }^{\text {a }, ~ M . K . ~ S a k h a r o v ~}{ }^{\text {a }}$, Y.M. Shulga ${ }^{\text {e }}$

${ }^{a}$ Institute of Solid State Physics RAS, 142432 Chernogolovka, Moscow District, Russia

${ }^{\mathrm{b}}$ Moscow State University, Leninskie gory, 119992 Moscow, Russia

${ }^{c}$ Chemical and Engineering Materials Division, Oak Ridge National Laboratory, Oak Ridge, TN 37831, USA

d Institute of Problems of Chemical Physics RAS, 142432 Chernogolovka, Moscow District, Russia

e National University of Science and Technology 'MISIS', Leninsky pr. 4, 119049 Moscow, Russia

\section{ABSTRACT}

A new hydrocarbon - hydrographite - with the composition close to $\mathrm{CH}$ is shown to form from graphite and gaseous hydrogen at pressures above $2 \mathrm{GPa}$ and temperatures from 450 to $700^{\circ} \mathrm{C}$. Hydrographite is a black solid thermally stable under ambient conditions. If heated in vacuum, it decomposes into graphite and molecular hydrogen at temperatures from 500 to $650^{\circ} \mathrm{C}$. Powder X-ray diffraction characterizes hydrographite as a multilayer "graphane II" phase predicted by $a b$ initio calculations [Wen X-D et al. PNAS 2011;108:6833] and consisting of graphane sheets in the chair conformation stacked along the hexagonal $\mathrm{c}$ axis in the $-\mathrm{ABAB}-$ sequence. The crystal structure of the synthesized phase belongs to the $\mathrm{P}_{3} \mathrm{mc}$ space group. The unit cell parameters are $\mathrm{a}=2.53(1) \AA$ and $\mathrm{c}=9.54(1) \AA$ and therefore exceed the corresponding parameters of graphite by $2.4(2) \%$ and $42.0(3) \%$. Stretching vibrations of C-H groups on the surface of the hydrographite particles are examined by infrared spectroscopy.

\footnotetext{
* Corresponding author.

E-mail address: antonov@issp.ac.ru (V.E. Antonov).
} 


\section{Introduction}

The past decades have demonstrated the effectiveness of high pressures for the synthesis of hydrocarbons. In particular, exposing different carbon and hydrogen donors to the $T$ - $P$ conditions characteristic of the Earth's upper mantle (pressures of a few GPa and temperatures of up to $1500^{\circ} \mathrm{C}$ ) resulted in the abiogenic synthesis of methane [1] and a hydrocarbon mixture $[2,3]$ similar in composition to the hydrocarbon part of the natural gas. Exposing single-wall carbon nanotubes (SWNTs) and graphite nanofibres (GNFs) to a hydrogen atmosphere at $P=9$ GPa and $T=450^{\circ} \mathrm{C}$ gave hydrocarbons never observed before [4].

These new hydrocarbons are black solids having $\mathrm{H} / \mathrm{C}$ atomic ratios of up to $x \approx 0.85$. Unlike the commonly studied SWNTs and GNFs with physisorbed $\mathrm{H}_{2}$ molecules easily leaving the samples at room and even liquid nitrogen temperature (see, e.g., review [5]), the new hydrocarbons are thermally stable. Particularly, the hydrogenated GNFs heated in vacuum at $20^{\circ} \mathrm{C} / \mathrm{min}$ begin evolving $\mathrm{H}_{2}$ at $500^{\circ} \mathrm{C}$, and the complete removal of the hydrogen requires annealing at $700^{\circ} \mathrm{C}$ [4]. An X-ray diffraction study showed that the hydrogenation of GNFs increases the interplanar spacing between their graphene layers by approximately $40 \%$, from 3.36 to $4.67 \AA$. The IR spectroscopy characterised the hydrogenated GNFs as mostly covalent compounds with two narrow vibrational bands at 2860 and $2920 \mathrm{~cm}^{-1}$, i.e., in the energy range typical of stretching $\mathrm{C}-\mathrm{H}$ vibrations [4].

In view of these findings, synthesis of hydrogenated crystalline graphite was a challenge. However, we failed to prepare it at $\mathrm{H}_{2}$ pressures as high as $9 \mathrm{GPa}$ and temperatures up to $450^{\circ} \mathrm{C}$ using plates of bulk graphite and graphite flakes as the starting materials.

At the same time, graphite was known to absorb hydrogen up to $x=0.95$ in the course of amorphization under intense ball milling (80 h at $400 \mathrm{rpm}$ ) at an $\mathrm{H}_{2}$ pressure of only $1 \mathrm{MPa}$ [6]. In order to activate the surface of the graphite without destroying its crystallinity, we ball milled its bulk pieces under rather mild conditions (30 min at $250 \mathrm{rpm}$ in Ar). Exposing the resulting graphite powder to $\mathrm{H}_{2}$ pressures of 4 to $7 \mathrm{GPa}$ at $450^{\circ} \mathrm{C}$ for a period of $24 \mathrm{~h}$ gave samples with the mean hydrogen content varying from $x=0.66$ to 0.94 . The samples were composed of a mixture of a new crystalline hydrocarbon with $x \approx 1$ (hydrographite for short) and unreacted graphite. The thermal stability, the spacing between the graphene layers and the energies of the stretching $\mathrm{C}-\mathrm{H}$ modes in the synthesized hydrographite proved to be similar to those of the hydrogenated GNFs. A single-phase sample of deuterated graphite with $\mathrm{D} / \mathrm{C}=1.06(5)$ was also produced and examined. In 2007, these preliminary results were briefly reported in [7]. 
All of a sudden, further studies of hydrographite were hampered by irreproducibility of its synthesis. After the first batch of the mechanically activated graphite was consumed, our attempts to prepare a new portion of such graphite using the same starting material and the same procedure of ball milling only gave powders that could be hydrogenated to $x \approx 0.2$. It was only recently that we have been able to raise the synthesis temperature to $700^{\circ} \mathrm{C}$ and began consistently producing samples with $x \approx 0.6-0.7$.

Meanwhile, the discovery of graphene (a flat monolayer of carbon atoms) [8,9] triggered a considerable interest to the synthesis of chemically modified carbon sheets. It was proposed that graphane, representing a graphene sheet saturated by hydrogen adsorbed from both sides, would be stable [10,11], and such a material was soon synthesized and experimentally studied [12]. There were extensive computer simulations [13-22] for the structure, electronic and vibrational properties of a single layer and bilayer graphane and also of a multilayer, bulk crystalline graphane. The principal conclusion was (see, e.g., Ref. [18]) that "a 3D graphane system might eventually be synthesized."

The hydrographite obtained in our experiments is likely to be this very 3D graphane system. The present paper discusses results of [7] in more detail, reports on our recent findings concerning the crystal structure of hydrographite and its stability at high hydrogen pressures and elevated temperatures and also provides a more likely interpretation of its IR spectra.

\section{Experimental}

The starting material was high-purity electrode graphite containing: $4 \times 10^{-5}$ wt. $\%$ Fe; $1 \times 10^{-4}$ wt.\% Si; $2 \times 10^{-5}$ wt.\% Ca and less than $1 \times 10^{-5}$ wt.\% of B, Mg, Mn, Al, Ti, Cu, V, Ni and Ag. About $2 \mathrm{~g}$ of this graphite together with a few stainless steel balls $10 \mathrm{~mm}$ in diameter were placed in a $250 \mathrm{~cm}^{3}$ stainless steel vial and ball-milled for $30 \mathrm{~min}$ at a rotation speed of $250 \mathrm{rpm}$ under an Ar atmosphere at room temperature using a planetary ball mill Fritsch Pulverisette 6.

To synthesize hydrographite, $100 \mathrm{mg}$ batches of this mechanically activated graphite powder were exposed to an atmosphere of gaseous hydrogen at fixed pressures ranging from 0.6 to $7.5 \mathrm{GPa}$ and temperatures from 350 to $800^{\circ} \mathrm{C}$ for periods varying from $24 \mathrm{~h}$ at $350^{\circ} \mathrm{C}$ to 30 min at $800^{\circ} \mathrm{C}$. The hydrogen was produced inside the high-pressure cell using thermal decomposition of an internal hydrogen source, $\mathrm{AlH}_{3}$ or $\mathrm{NH}_{3} \mathrm{BH}_{3}$, incased into a tightly plugged copper capsule together with the graphite powder and separated from it by a thin layer of Pd (the method is described in more detail in [23]; the experiments were carried out using a quasihydrostatic Toroid-type high-pressure chamber [24]). After the hydrogenation was 
complete, the sample was cooled to $80 \mathrm{~K}$ or to room temperature, recovered to the ambient pressure and further stored in liquid nitrogen until the measurements.

A few samples of deuterated graphite were produced in a similar way using $\mathrm{AlD}_{3}$ as the internal deuterium source in the high-pressure cell. This aluminium deuteride was slightly contaminated with protium and had an atomic ratio of $\mathrm{H} /(\mathrm{D}+\mathrm{H})=0.029(2)$ according to massspectrometry [25].

The hydrogen evolution from the prepared $\mathrm{C}-\mathrm{H}$ samples and the total hydrogen content of these samples were examined by thermodesorption of the gas into a pre-evacuated measuring system in the regime of heating to $660^{\circ} \mathrm{C}$ at rates of 10 or $20^{\circ} \mathrm{C} / \mathrm{min}$. The amount of hydrogen remaining in the samples after a one day exposure to room temperature was also determined for a few samples by combustion in a flow of oxygen at $1400^{\circ} \mathrm{C}$ followed by weighting the resultant $\mathrm{CO}_{2}$ and $\mathrm{H}_{2} \mathrm{O}$ (analyzer "Vario Micro Cube", Elementar $\mathrm{GmbH}$ ). In both methods, the mean H/C atomic ratio was measured with a relative accuracy of $5 \%$.

Samples of the initial and hydrogenated and dehydrogenated graphite were studied at room temperature by powder X-ray diffraction using a Siemens D500 diffractometer with $\mathrm{Cu} \mathrm{K \alpha}$ radiation selected by a diffracted beam monochromator. Atomic vibrations in these substances were characterized by IR transmission spectra measured at room temperature with a Bruker IFS$113 \mathrm{v}$ Fourier spectrometer in the range $400-5000 \mathrm{~cm}^{-1}$ with a resolution of $4 \mathrm{~cm}^{-1}$. The samples for the IR spectroscopy were in the form of pellets pressed from mixtures of a powder of the initial or hydrogenated graphite with a powder of $\mathrm{KBr}$.

\section{Results and discussion}

\subsection{Hydrogen content and thermal stability of quenched samples of hydrographite}

To estimate the thermodesorption characteristics of the graphite- $\mathrm{H}$ samples synthesized under high hydrogen pressures, a $0.5-5 \mathrm{mg}$ portion of the quenched sample was first encased into a thin-wall non-hermetic copper container submerged in liquid nitrogen. The container was then dropped to the bottom of a quartz ampoule cooled by liquid nitrogen from outside. The ampoule, with its lower end still submerged in the nitrogen bath, was vertically attached to the measuring system and the system was pumped out to a pressure of $2 \times 10^{-3}$ Torr. After that, the lower part of the quartz ampoule with the incased sample was heated at a rate of 20 or $10^{\circ} \mathrm{C} / \mathrm{min}$ and the amount of the gas releasing from the sample was determined from the pressure in the system.

Fig. 1A shows typical desorption curves for the graphite- $\mathrm{H}$ and graphite-D samples. The curves are constructed assuming that the evolved gas was molecular hydrogen (deuterium). Fig. 
1B compares a curve for the hydrogenated graphite measured at $20^{\circ} \mathrm{C} / \mathrm{min}$ with those for the hydrogenated graphite nanofibres and single-walled nanotubes measured earlier [4] at the same heating rate.

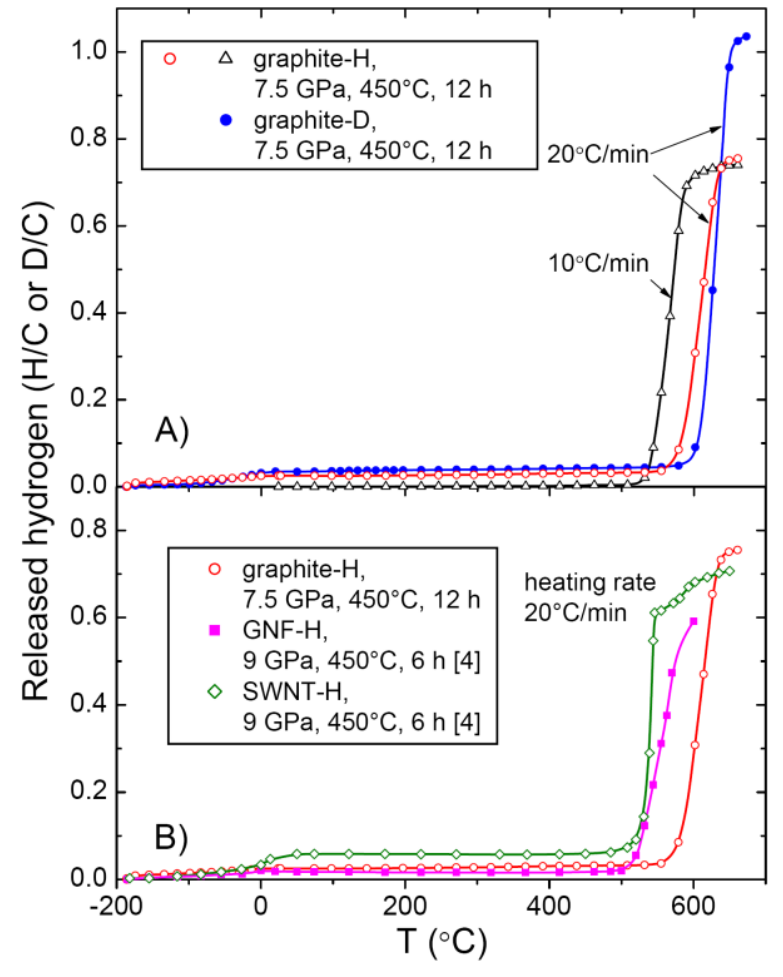

Fig. 1 - Temperature dependences of the amount of hydrogen (deuterium) released from quenched graphite- $\mathrm{H}$ and graphite-D samples (results of the present work) and GNF-H and SWNT-H samples (results of [4]) heated at a rate of 20 or $10^{\circ} \mathrm{C} / \mathrm{min}$ in a closed-volume, preevacuated measuring system. The gas pressures and temperature of the sample synthesis are indicated in the legends to the symbols. The dependence shown in (A) by open triangles is for the graphite-H sample preliminarily exposed to room temperature for 1 day.

As seen from Fig. 1, the desorption curves for the hydrogenated graphite, GNFs and SWNTs look similar and the gas release is a two-stage process. In heating the sample from $77 \mathrm{~K}$ to approximately room temperature, the amount of the liberated gas gradually increases, reaches a rather small but still reliably detectable atomic $\mathrm{H} / \mathrm{C}$ ratio of $x \approx 0.02-0.05$ and nearly stops changing. Most hydrogen is evolved at the second stage that starts above $500^{\circ} \mathrm{C}$ and stops around $650^{\circ} \mathrm{C}$.

The occurrence of the two well-separated stages in the thermodesorption curves suggests that the quenched hydrocarbons contain hydrogen in two different forms. In the case of the quenched SWNT-H sample with $x \approx 0.61$ synthesized at $3 \mathrm{GPa}$ and $350^{\circ} \mathrm{C}$, these two forms of the absorbed hydrogen have been identified by inelastic neutron scattering [26]. The weakly bonded hydrogen $(x \approx 0.05)$ leaving the sample upon heating to room temperature was shown to be the physisorbed $\mathrm{H}_{2}$ molecules exhibiting nearly free rotational behaviour, while most $\mathrm{H}$ atoms $(x=0.56)$ were covalently bound to the carbon atoms and could only be removed by heating to $\mathrm{T}$ $>500^{\circ} \mathrm{C}$. The two forms of hydrogen contained in our samples of hydrogenated graphite and GNFs are likely to be the same. This paper will further deal with the covalently bound hydrogen remaining in the samples under ambient conditions, and the hydrogen content of the samples will refer to this hydrogen only. 
Our assumption that the high-pressure hydrocarbons heated in vacuum above $500^{\circ} \mathrm{C}$ should emit molecular hydrogen nearly free of volatile hydrocarbons like $\mathrm{CH}_{4}, \mathrm{C}_{2} \mathrm{H}_{6}$, etc., was based on results for the hydrogenated SWNTs studied by mass spectrometry [27]. To check if this is also true for hydrographite, we analyzed a few graphite-H and graphite-D samples by combustion in an oxygen flow at $1400^{\circ} \mathrm{C}$. The analysis of $2 \mathrm{mg}$ portions of the samples exposed to ambient conditions for one day gave virtually the same contents of the covalently bonded hydrogen as the thermodesorption did. For example, the graphite-D sample that released $x \approx 1.04-0.04=$ $1.00(5)$ of deuterium in heating from room temperature to $670^{\circ} \mathrm{C}$ (see Fig. 1A) was shown to have $x=1.06(5)$ by the combustion analysis. Such an agreement evidences that in the thermodesorption experiments:

- nearly all hydrogen was evolved in the form of $\mathrm{H}_{2}$ molecules rather than gaseous hydrocarbons (e.g., if methane $\mathrm{CH}_{4}$ were released, the number of its molecules and, correspondingly, the pressure would be twice as low);

- nearly all hydrogen was evolved at temperatures below $650^{\circ} \mathrm{C}$ (otherwise, the combustion at $1400^{\circ} \mathrm{C}$ would detect more hydrogen than the thermodesorption).

It seems worth mentioning in this connection that another graphite-based hydrocarbon, the nanostructured material with $x \approx 0.95$ produced by intensive ball-milling of graphite in an $\mathrm{H}_{2}$ atmosphere [6], was also thermally stable. According to the mass spectra measured in [28], it also evolved nearly pure $\mathrm{H}_{2}$ when heated in vacuum. At the same time, the kinetics of the hydrogen desorption from the nanostructured material were quite different. This material released hydrogen in two steps starting at $\approx 330$ and $\approx 680^{\circ} \mathrm{C}$, respectively, [28] whereas the crystalline hydrographite and other high-pressure hydrocarbons evolved most hydrogen in one step starting at $500-600^{\circ} \mathrm{C}$ (see Fig. 1). The origin of the first step in the desorption curve of the nanostructured graphite is not well understood. The second step occurred near the recrystallization temperature of the studied samples and it was tentatively attributed to the release of the hydrogen atoms trapped at carbon dangling bonds [28].

As for the kinetics of hydrogen desorption from the crystalline hydrographite, the position and width of the temperature interval of the intensive hydrogen release proved to be mostly insensitive to the type of the hydrogen isotope, protium or deuterium (compare the curves in Fig. $1 \mathrm{~A}$ for the graphite-D and graphite-H samples measured at $\left.20^{\circ} \mathrm{C} / \mathrm{min}\right)$. A decrease in the heating rate from 20 to $10^{\circ} \mathrm{C} / \mathrm{min}$ lowered the starting temperature of the hydrogen release by $30-50^{\circ} \mathrm{C}$, from about 560 to $520^{\circ} \mathrm{C}$ (compare the dependences in Fig. 1A for two different portions of the same graphite-H sample). A one day vacuum annealing of a graphite- $\mathrm{H}$ sample at $450^{\circ} \mathrm{C}$ only resulted in the desorption of a few per cent of its total hydrogen content. Compared to other 
high-pressure hydrocarbons, GNF-H and SWNT-H, hydrographite is a little more thermally stable (see Fig. 1B).

\subsection{Crystal structure of hydrographite}

Fig. 2 shows an X-ray diffraction pattern of the initial ball-milled graphite, which was further used to synthesize the graphite- $\mathrm{H}$ and graphite-D samples under high gas pressures. The considerable broadening of the $(00 \ell)$ lines toward low angles is typical of the ball-milled graphite $[29,30]$ and mainly results from fracturing the graphite particles and the formation of stacking faults, dangling bonds and other defects. The shape of the (002) line can roughly be described by the approximately equal contributions from two types of grains with the $\mathrm{P} 6_{3} / \mathrm{mmc}$ structure. These are the crystallites with $\mathrm{a}=2.47 \AA, \mathrm{c}=6.72 \AA$ and the coherence length $\mathrm{L}_{\mathrm{c}}=13$ $\mathrm{nm}$ in the direction of the hexagonal axis (thin solid curve in Fig. 2) and nanocrystals with $\mathrm{a}=$ $2.50 \AA, \mathrm{c}=7.10 \AA$ and $\mathrm{L}_{\mathrm{c}}=4 \mathrm{~nm}$ (the dashed curve). The coherence lengths are estimated using Scherrer's equation $\mathrm{L}_{c}=1.5 \lambda /(\Delta \cdot \cos \theta)$, where $\lambda$ is the wavelength of the $\mathrm{Cu} \mathrm{K} \alpha$ radiation and $\theta$ and $\Delta$ are, respectively, the angle and the half-width at half-maximum of the (002) peak.

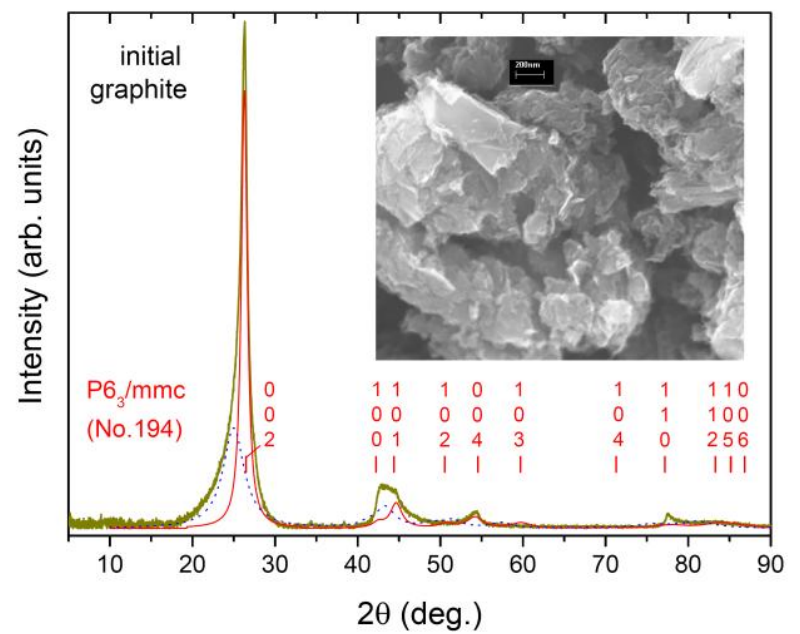

Fig. 2 - X-ray diffraction pattern of the ballmilled graphite used to synthesize the graphite$\mathrm{H}$ and graphite-D samples [7]. Room temperature, $\mathrm{Cu} \mathrm{K} \alpha$ radiation. The smooth background is subtracted. The inset shows an SEM image obtained from the same graphite powder using a high-resolution scanning electron microscope Zeiss Supra 50 VP.

As seen from the SEM micrograph in the inset in Fig. 2, our ball-milled graphite was composed of agglomerated platelets typical of graphite powders (SEM images of the hydrogenated samples looked similar). The surface of these platelets is parallel to the ab-planes of the hexagonal crystal lattice of graphite and perpendicular to the c-axis. The dimensions of the platelets reach $200 \times 400 \mathrm{~nm}^{2}$ and therefore exceed the coherence length $\mathrm{L}_{\mathrm{c}}$ in the c-direction by an order of magnitude. Correspondingly, the reciprocal lattice sites should be shaped like rods oriented along the reciprocal $\mathrm{c}^{*}$-axis. This suggests that the width of the lines in the diffraction pattern of such a powder should strongly depend on their Miller indices. As a result, profile analysis of diffraction patterns of the initial and hydrogenated graphite samples could only be performed on a semi-quantitative level in the present paper. 
The bottom spectrum in Fig. 3 represents an X-ray diffraction pattern of a single-phase sample of deuterated graphite with the composition $\mathrm{CD}_{1.06(5)}$. The most prominent feature of this pattern is a shift of the (002) diffraction line of graphite to lower angles corresponding to the approximately $42 \%$ increase in the c-parameter of the hexagonal lattice of graphite, from 6.72 to $9.54 \AA$. The line also becomes less broadened from the left-hand side. Presumably, this is due to the partial annealing of defects in the course of hydrogenation of the ball-milled graphite at an elevated temperature of $450^{\circ} \mathrm{C}$. Using Scherrer's equation, the width of the (002) line gives the coherence length $\mathrm{L}_{\mathrm{c}}=10 \mathrm{~nm}$.

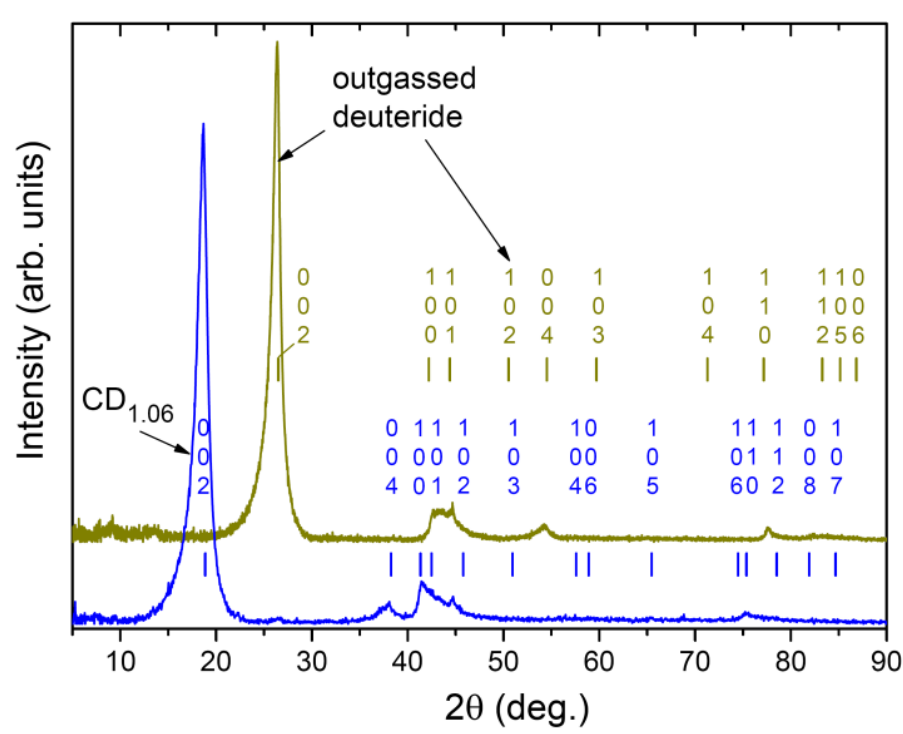

Fig. 3 - X-ray diffraction pattern of the graphite-D sample with $\mathrm{D} / \mathrm{C}=1.06(5)$ synthesized at a $\mathrm{D}_{2}$ pressure of $7.5 \mathrm{GPa}$ and $\mathrm{T}=450^{\circ} \mathrm{C}[7]$ (the bottom spectrum) and a pattern of the same sample after the complete removal of deuterium by a $4 \mathrm{~h}$ annealing at $600^{\circ} \mathrm{C}$ in vacuum (the spectrum is shifted upwards). Room temperature, $\mathrm{Cu} \mathrm{K \alpha}$ radiation, subtracted background.

After the $\mathrm{CD}_{1.06}$ sample is fully outgassed at $600^{\circ} \mathrm{C}$ in vacuum, the width of its (002) line further decreases and corresponds to $\mathrm{L}_{\mathrm{c}}=14 \mathrm{~nm}$ (the upper spectrum in Fig. 3). The lattice parameters of the degassed sample revert to those of the fraction with $L_{c}=13 \mathrm{~nm}$ in the initial graphite and the X-ray patterns of both the initial (Fig. 2) and degassed (Fig. 3) graphite samples can satisfactorily be described in the $\mathrm{P}_{3} / \mathrm{mmc}$ space group. The structural parameters resulted from the (semi-quantitative) profile analysis of the diffraction pattern of the outgassed sample are presented in Table 1. We chose this sample as the reference state of the non-hydrogenated graphite, because comparison of the hydrogenated graphite with the starting graphite would be more ambiguous due to the much stronger and asymmetrical broadening of its diffraction lines.

The diffraction pattern of the deuterated sample $\mathrm{CD}_{1.06}$ was modeled on the basis of a graphite-like crystal structure (space group $\mathrm{P}_{3} / \mathrm{mmc}$ ) and the structures of the two forms of multilayer graphane, "graphane I" and "graphane II", which are most stable at T = $0 \mathrm{~K}$ and pressures below $10 \mathrm{GPa}$ according to the $a b$ initio calculations of Ref. [18]. The structure of "graphane I" belongs to the P3m1 space group (in Ref. [18], it was misprinted as P $3 \mathrm{ml}$ ) and the space group of "graphane II" is $\mathrm{P}_{3} \mathrm{mc}$. The resulting profile fits are shown in Fig. 4. 
Table 1 - Structural parameters of the graphite-D sample with $\mathrm{D} / \mathrm{C}=$ 1.06(5) and of pure graphite produced by outgassing this graphite-D sample at $600^{\circ} \mathrm{C}$ in vacuum. The parameters are obtained by a profile analysis of the X-ray diffraction patterns of these samples presented in Fig. 3. Positions of the D atoms could not be reliably determined from experiment and these atoms are placed at a distance of $0.12 \mathrm{c} \approx$ $1.1 \AA$ in the c-direction from the nearest $\mathrm{C}$ atom in accordance with results of most $a b$ initio calculations for the chair conformation of graphane.

\begin{tabular}{|c|c|c|c|}
\hline Sample & graphite (outgassed) & \multicolumn{2}{|c|}{ graphite-D } \\
\hline $\mathrm{D} / \mathrm{C}$ atomic ratio & 0 & \multicolumn{2}{|l|}{$1.06(5)$} \\
\hline Space group & $\mathrm{P}_{3} / \mathrm{mmc}($ No. 194$)$ & \multicolumn{2}{|c|}{$\mathrm{P}_{3} \mathrm{mc}$ (No. 186) } \\
\hline $\begin{array}{l}\text { Positions } \\
\text { of } \mathrm{C} \text { atoms }\end{array}$ & $2 \mathrm{c}(1 / 3,2 / 3,1 / 4)$ & \multicolumn{2}{|c|}{$\begin{array}{l}2 \mathrm{a}(0,0,0) \\
2 \mathrm{~b}(1 / 3,2 / 3,0.05)\end{array}$} \\
\hline $\begin{array}{l}\text { Tentative positions } \\
\text { of } D \text { atoms }\end{array}$ & & \multicolumn{2}{|c|}{$\begin{array}{l}2 \mathrm{a}(0,0,0.88) \\
2 \mathrm{~b}(1 / 3,2 / 3,0.17)\end{array}$} \\
\hline & & & Increase $(\%)$ \\
\hline $\mathrm{a}(\AA)$ & $2.47(1)$ & $2.53(1)$ & $2.4(2)$ \\
\hline$c(\AA)$ & $6.72(1)$ & $9.54(1)$ & $42.0(3)$ \\
\hline $\mathrm{c} / \mathrm{a}$ & $2.72(1)$ & $3.77(2)$ & $39(1)$ \\
\hline $\mathrm{V}\left(\AA^{3} /\right.$ atom $\left.\mathrm{C}\right)$ & $35.5(3)$ & $52.9(4)$ & $49(2)$ \\
\hline
\end{tabular}

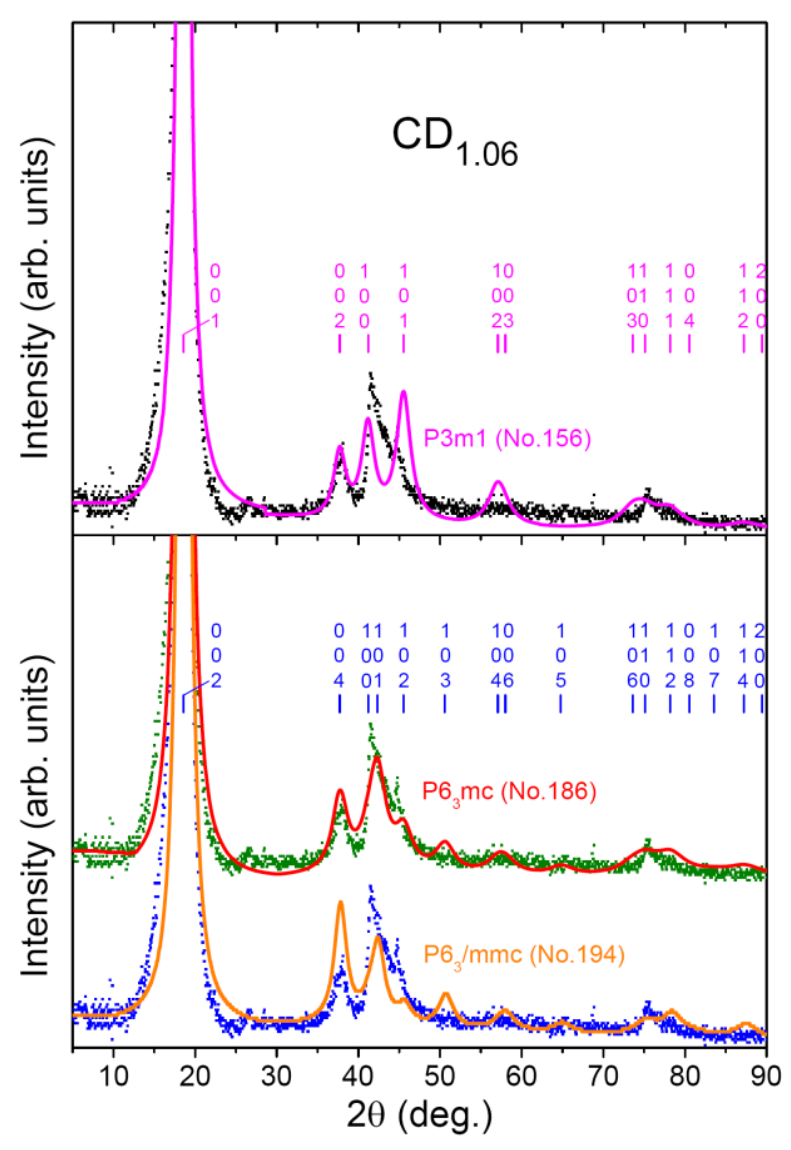

Fig. 4 - Experimental X-ray pattern of the $\mathrm{CD}_{1.06}$ sample (solid squares; the same data as in Fig. 3) and results of its semiquantitative profile analysis in the framework of the $\mathrm{P} 6_{3} / \mathrm{mmc}$ and $\mathrm{P}_{3} \mathrm{mc}$ and P3m1 space groups (solid curves). The cparameter of the $\mathrm{P} 3 \mathrm{~m} 1$ structure is twice as small as that of the $\mathrm{P}_{3} / \mathrm{mmc}$ and $\mathrm{P} 6_{3} \mathrm{mc}$ structures. 
As seen from Fig. 4, the intensity distribution among the diffraction lines in the angular range $30<2 \theta<50^{\circ}$ can semi-quantitatively be reproduced in the $\mathrm{P}_{3} \mathrm{mc}$ space group, whereas the $\mathrm{P}_{3} / \mathrm{mmc}$ and $\mathrm{P} 3 \mathrm{~m} 1$ groups give qualitatively inadequate distributions. The inapplicability of the $\mathrm{P}_{3} / \mathrm{mmc}$ group is not surprising, because none of the ab initio calculations has ever predicted a graphite-like structure for a single layer or bilayer or multilayer graphane. As for the predicted $\mathrm{P} 3 \mathrm{~m} 1$ and $\mathrm{P}_{3} \mathrm{mc}$ structures [18], they are built from similar $\mathrm{CH}$ graphane layers in the chair conformation and only differ from each other by the stacking sequences of these layers along the c-axis. Namely, these are the -AAAA- sequence in the case of the P3m1 phase and $\mathrm{ABAB}-$ sequence for the $\mathrm{P}_{3} \mathrm{mc}$ phase.

Due to the weak interactions between the layers in a graphane crystal, the differences in the calculated enthalpies [18] of the $\mathrm{P} 3 \mathrm{~m} 1$ and $\mathrm{P}_{3} \mathrm{mc}$ stacking polymorphs were too small to determine which of these phases is more stable at $\mathrm{T}=0 \mathrm{~K}$ and pressures up to $120 \mathrm{GPa}$. Our Xray results (Fig. 4) are in favour of the $\mathrm{P}_{3} \mathrm{mc}$ structure of the $\mathrm{CD}_{1.06}$ phase. We think that $\mathrm{P}_{3} \mathrm{mc}$ is the most likely structure of this phase because all other possible forms of multilayer graphane are considerably less stable than the $\mathrm{P} 3 \mathrm{~m} 1$ and $\mathrm{P}_{3} \mathrm{mc}$ ones at pressures up to $10 \mathrm{GPa}$ [18], while our $\mathrm{CD}_{1.06}$ sample was synthesized at a lower pressure of $7.5 \mathrm{GPa}$ and studied by X-ray diffraction at ambient pressure.

Refined parameters of the $\mathrm{P}_{3} \mathrm{mc}$ structure of the $\mathrm{CD}_{1.06}$ phase ("graphane II" structure according to Ref. [18]; -ABAB- stacking; 4 CD pairs in the unit cell) are listed in the rightmost column of Table 1. As one can see, the hydrogenation of graphite resulted in the increase of its atomic volume by nearly $50 \%$, and this increase was mostly due to the elongation of the cparameter by $42 \%$.

A schematic representation of the $\mathrm{P}_{3} \mathrm{mc}$ structure of such a graphane crystal is given in Fig. 5. This is the so-called "buckled" structure composed of weakly coupled single graphane layers in the chair conformation, in which every alternate carbon atom is attached to the hydrogen atom from alternate sides of the plane and displaced out of the hexagonal plane (buckled) toward this hydrogen atom. The profile refinement gave a value of $\delta \mathrm{z} \approx 0.05 \mathrm{c} / 2 \approx 0.25$ $\AA$ for the displacement in the $\mathrm{CD}_{1.06}$ compound (see Table 1). Such a displacement leads to the significantly increased minimum distance $\mathrm{d}_{\mathrm{C}-\mathrm{C}}=1.54 \AA$ 年etween the neighboring carbon atoms in the buckled structure compared with $\mathrm{d}_{\mathrm{C}-\mathrm{C}}=a / \sqrt{3} \approx 1.46 \AA$ in a flat carbon layer $(\delta \mathrm{z}=0)$ with the same lattice parameter $\mathrm{a}=2.53 \AA$. The distance $\mathrm{d}_{\mathrm{C}-\mathrm{C}}=1.54 \AA$ agrees with predictions of most $a b$ initio calculations (see, e.g., $[13,18]$ ) thus favoring the chair conformation of the graphane layers chosen to model the $\mathrm{CD}_{1.06}$ structure. 


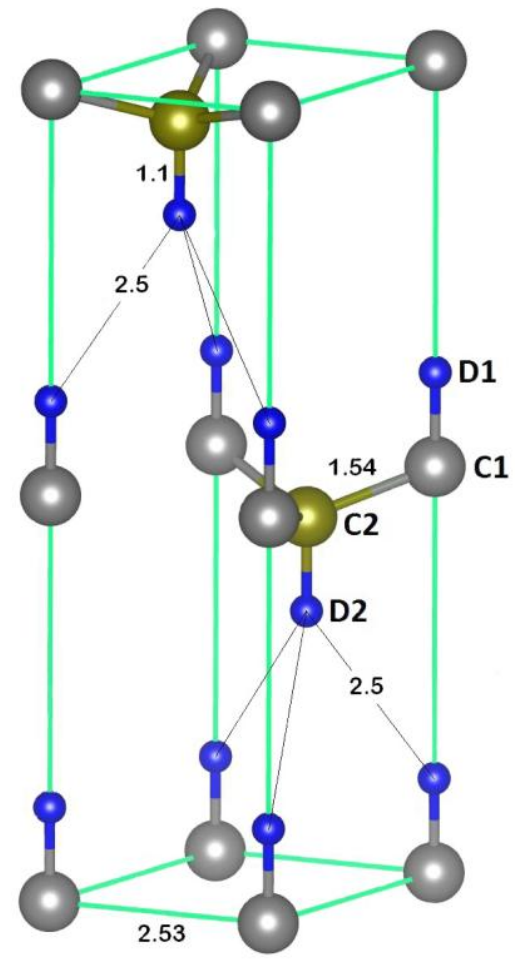

Fig. 5 - The $\mathrm{P}_{3} \mathrm{mc}$ structure of a graphane crystal (see Table 1). Large spheres represent $C$ atoms; small spheres stand for $\mathrm{D}$ atoms. The atoms labeled $\mathrm{C} 1$ and $\mathrm{D} 1$ sit on the $2 \mathrm{a}$ positions; those labeled $\mathrm{C} 2$ and $\mathrm{D} 2$ are on the $2 \mathrm{~b}$ positions. Numbers indicate the interatomic distances in Angstroms.

The experimental interplanar distance $\mathrm{c} / 2=4.77(1) \AA$ in the $\mathrm{CD}_{1.06}$ sample agrees with the predicted distance between the graphane layers in multilayer graphane: $4.978 \AA$ [11]; 5-6 $\AA$ [13] and 4.5-4.8 $\AA$ [19]. All ab initio calculations also predict that the in-plane parameter, a, of the single-, bi- and multilayer graphane in the chair conformation should be larger than $\mathrm{a}_{0} \approx 2.47 \AA$ of graphite. In the case of the multilayer graphane, the calculations give $\mathrm{a}=2.516 \AA[11]$ and $\mathrm{a}=$ $2.545 \AA$ [13]. The experimental value of $\mathrm{a}=2.53(1) \AA$ for our $\mathrm{CD}_{1.06}$ sample lies in between the predicted values.

The calculations for multilayer graphanes also showed that the in-plane periodicity in the graphane layers is virtually insensitive to the weak interaction between different layers. Therefore, the stable chair conformation of the single-layer graphane is likely to have $\mathrm{a} \approx 2.53 \AA$ in accordance with both the calculations and our experimental result for hydrographite. At the same time, most samples of the single-layer graphane synthesized in [12] had the in-plane periodicity (called the d-parameter), which was smaller by $1-5 \%$ than $\mathrm{a}_{0} \approx 2.47 \AA$ of graphite. We think it was a non-equilibrium result. A discussion of its possible origin can be found in [13].

\subsection{Formation and decomposition of hydrographite under high hydrogen pressure}

The $\mathrm{CD}_{1.06}$ sample discussed above was the only single-phase sample of multilayer graphane examined in the present work. X-ray diffraction studies of a few dozens of other graphite-D and graphite-H samples synthesized at pressures from $2.5-7.5 \mathrm{GPa}$ and temperatures $350-700^{\circ} \mathrm{C}$ 
showed them to consist of a two-phase mixture of unreacted graphite and a hydrographite phase with the same lattice parameters as that of the $\mathrm{CD}_{1.06}$ phase. The unreacted fraction of the samples was usually composed of the largest grains and its (002) line was clearly visible in the diffraction patterns. Particularly, such a line was seen in the pattern of the graphite-H sample with the mean atomic ratio $\mathrm{H} / \mathrm{C}=0.94(5)$. We therefore conclude that the high-pressure hydrogenation of graphite always proceeded as a two-phase reaction and the final product of this reaction was a multilayer graphane with the composition close to $\mathrm{CH}$.

Fig. 6 shows the maximal yield of hydrographite at $450^{\circ} \mathrm{C}$ estimated by the ratio of intensities of the strongest (002) lines of hydrographite and unreacted graphite in the studied graphite-H samples. As one can see, hydrographite was only formed at hydrogen pressures above $2 \mathrm{GPa}$.

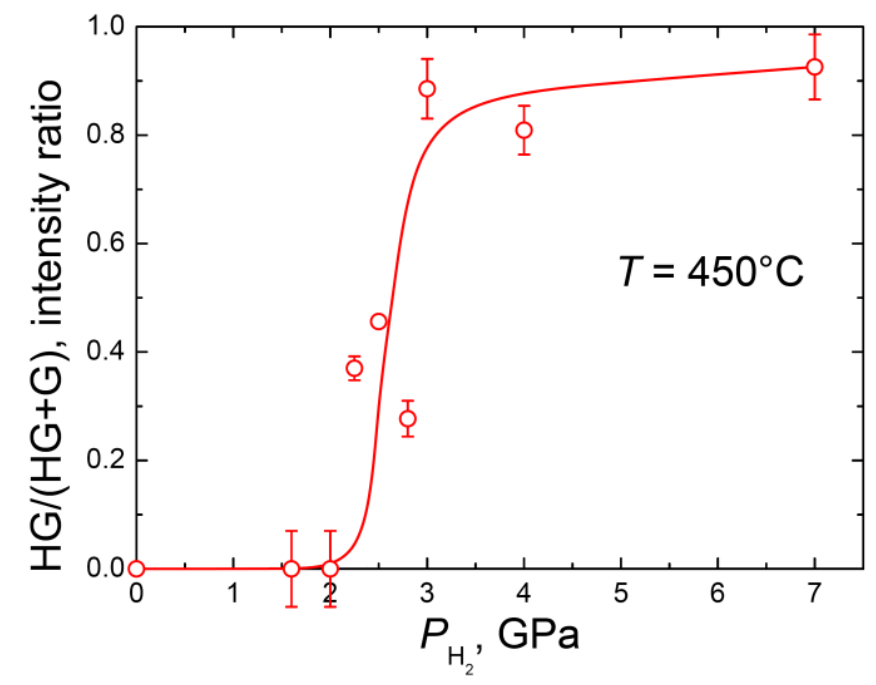

Fig. 6 - The maximal ratio $\mathrm{HG} /(\mathrm{HG}+\mathrm{G})$ of the integral intensities of the (002) lines of hydrographite $(\mathrm{HG})$ and graphite (G) in the two-phase "graphite + hydrographite" samples synthesized by $24 \mathrm{~h}$ exposures of ball-milled graphite to an $\mathrm{H}_{2}$ atmosphere at $450^{\circ} \mathrm{C}$ and pressures indicated along the $\mathrm{x}$-axis.

Exposing the ball-milled graphite for a few hours to a hydrogen pressure of $7.5 \mathrm{GPa}$ at temperatures from 530 to $630^{\circ} \mathrm{C}$ gave samples with $\mathrm{H} / \mathrm{C}=0.6-0.7$, which contained, correspondingly, 60-70 mol.\% hydrographite. An increase in the synthesis temperature to $700^{\circ} \mathrm{C}$ did not increase the yield of hydrographite and at temperatures above $720^{\circ} \mathrm{C}$, hydrographite did not often form at all.

To examine the decomposition conditions of hydrographite at an $\mathrm{H}_{2}$ pressure of $7.5 \mathrm{GPa}$, we used a graphite- $\mathrm{H}$ sample synthesized at $7.5 \mathrm{GPa}$ and $530^{\circ} \mathrm{C}$ and weighing about $100 \mathrm{mg}$. The sample had H/C = 0.69 and consisted of a mixture of approximately $69 \mathrm{~mol} \%$ hydrographite and $31 \mathrm{~mol} . \%$ unreacted graphite. Exposing small portions (about $3 \mathrm{mg}$ ) of this sample to the hydrogen pressure $7.5 \mathrm{GPa}$ and temperatures up to $630^{\circ} \mathrm{C}$ resulted in an increase in their hydrogen content. At $700^{\circ} \mathrm{C}$, the $\mathrm{H} / \mathrm{C}$ ratio remained virtually unchanged. At $720-750^{\circ} \mathrm{C}$, it did not change in some samples and decreased to $\mathrm{H} / \mathrm{C} \approx 0.02-0.03$ in some other samples. At $\mathrm{T} \geq$ 
$775^{\circ} \mathrm{C}$, the hydrogen content of all studied samples decreased to $\mathrm{H} / \mathrm{C} \approx 0.02-0.03$. In addition, the samples with this small hydrogen content lost about $2 / 3$ of their initial mass.

The most plausible explanation of the observed effects is that under a hydrogen pressure of 7.5 GPa, hydrographite remains stable in respect to the decomposition into graphite and molecular $\mathrm{H}_{2}$ at temperatures up to about $720^{\circ} \mathrm{C}$. However, starting with this temperature, hydrographite becomes thermally unstable relative to the formation of methane and/or other light hydrocarbons. These hydrocarbons are fluids under the experimental conditions and they mostly leave the sample and mix with the hydrogen gas and sop in the debris of the high-pressure cell. The carryover of about $69 \mathrm{~mol} \%$ hydrographite from the solid sample leads to the loss of approximately $2 / 3$ of its overall mass and this is what the experiment shows. The $31 \mathrm{~mol} \%$ of the unreacted graphite contained in the starting sample remains intact, because the synthesis of methane and other light hydrocarbons from graphite and $\mathrm{H}_{2}$ requires higher temperatures due to the slow kinetics of the process (see, e.g., [1-3]).

\subsection{Infrared spectra of hydrographite}

Figure 7 presents IR transmission spectra of our ball-milled graphite and the samples of hydrogenated and deuterated graphite with the maximal $\mathrm{H}$ or D concentrations. As discussed in Section 3.2, X-ray diffraction showed the $\mathrm{CD}_{1.06}$ sample to be single-phase hydrographite. The $\mathrm{CH}_{0.94}$ sample contained a few percent of unreacted graphite (the composition of this sample is indicated by the rightmost point in Fig. 6). Prior to each IR measurement, a portion of $0.014 \mathrm{mg}$ of a powdered sample was mixed with $80 \mathrm{mg}$ of $\mathrm{KBr}$ powder and compacted at a pressure of 0.7 $\mathrm{GPa}$ into pellets with a diameter of $6 \mathrm{~mm}$ and thickness of $0.5 \mathrm{~mm}$. Using the similarly prepared pellets allowed a direct comparison of the light transmission by the studied samples.

The IR spectrum of the graphite powder shows a monotonic decrease in the light transmittance $T$ with increasing photon frequency $v$. Such a featureless IR spectrum is typical of the ball-milled graphite [31]. The spectra of the $\mathrm{CH}_{0.94}$ and $\mathrm{CD}_{1.06}$ samples demonstrate a similar overall monotonic decrease in the light transmittance with increasing photon energy together with the appearance of narrow absorption bands in the energy range characteristic of the stretching $\mathrm{C}-\mathrm{H}$ and $\mathrm{C}-\mathrm{D}$ vibrations in hydrocarbons. 


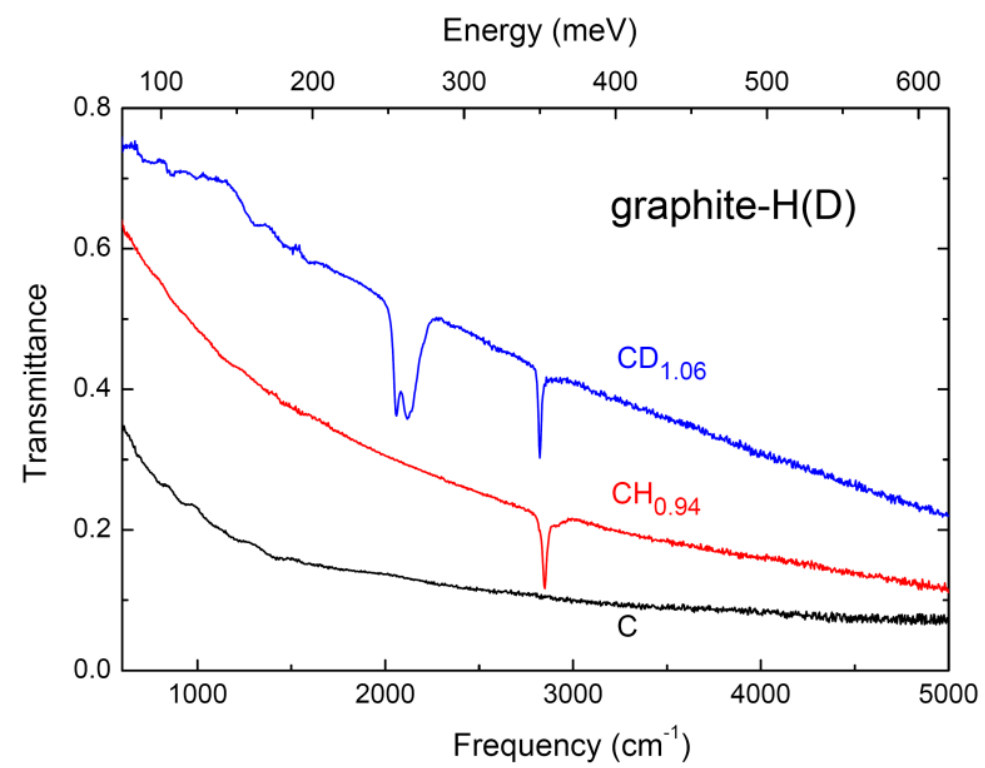

Fig. 7 - IR transmission spectra, T(v), of the ball-milled graphite powder (curve "C") and the samples $\mathrm{CH}_{0.94}$ (synthesized at a hydrogen pressure of $7 \mathrm{GPa}$ and $\mathrm{T}=450^{\circ} \mathrm{C}$ ) and $\mathrm{CD}_{1.06}$ (synthesized at a deuterium pressure of $7.5 \mathrm{GPa}$ and $\mathrm{T}=450^{\circ} \mathrm{C}$ ). The absorption band near $v=$ $2820 \mathrm{~cm}^{-1}$ in the $\mathrm{CD}_{1.06}$ spectrum is due to the $\mathrm{H}$ impurity in the sample. Bruker IFS-113v Fourier spectrometer, room temperature. (Results of Ref. [7].)

As one can see from Fig. 7, within the whole studied energy range, the total light transmittance of $\mathrm{CH}_{0.94}$ and $\mathrm{CD}_{1.06}$ is approximately 2 and 4 times higher than that of the graphite. Light transmittance of a conducting powder is mostly determined by the light scattering on small particles and by the light absorption by free charge carriers in these particles [32]. The monotonic decrease in the light transmittance with increasing photon energy observed in each of the three studied samples is characteristic of scattering on the particles with the dimensions of the order of or less than the wavelength of the incident light. The studied range $600<v<5000$ $\AA^{-1}$ (see Fig. 7) corresponds to wavelengths of $17>\lambda>2 \mu \mathrm{m}$. This suggests that the light should have been scattered by agglomerates the size of up to $\approx 20 \mu \mathrm{m}$ formed by the much smaller platelets of graphite or hydrographite, whose maximum dimension was about $0.4 \mu \mathrm{m}$ (see Section 3.2).

We could not directly compare the sizes of the agglomerates of graphite and hydrographite platelets mixed with $\mathrm{KBr}$ in the samples studied by IR spectroscopy. However, the similarity in the spectral dependences $T(v)$ is indicative of similar sizes of the scattering particles (agglomerates) in the samples of the virgin and hydrogenated graphite. We therefore consider it most likely that the strong increase in the light transmittance by the hydrogenated graphite is mostly caused by the decrease in the intensity of the scattered light due to the lower conductivity of free charge carriers in hydrographite compared to graphite. 
Such a conclusion agrees with results of ab initio calculations of the electronic structure of single layer and multilayer graphanes, all of them predicting an insulating or semiconducting behaviour of these materials (see [18] and references therein). The presence of the impurity of highly conductive graphite in the $\mathrm{CH}_{0.94}$ sample can explain (at least, partly) its smaller light transmittance compared to the single-phase $\mathrm{CD}_{1.06}$ sample.

In order to analyze the narrow absorption bands observed in the IR spectra of hydrogenated graphite samples in the range of the C-H and C-D stretching vibrations, transmittance $\mathrm{T}(v)$ of a few samples was first formally converted to absorption defined as $A^{*}(v)=-\ln (T)$. From these $A^{*}(v)$ spectra we then subtracted the monotonic "baselines" resulting predominantly from the light scattering discussed above. The $\mathrm{A}(\mathrm{v})$ spectra thus obtained are shown in Figs. 8 and 9 and expected to mostly represent the light absorption due to the excited stretching vibrations of the C-H and C-D bonds.

According to the $a b$ initio calculations, the $\mathrm{C}-\mathrm{H}$ stretching vibrations in a single-layer graphane [14,21] and a multilayer graphane [18] in the chair conformation should form a narrow band far above the bands of other vibrations, in the range $2830<v<2890 \mathrm{~cm}^{-1}[14,18]$ or 2730 $<v<2780 \mathrm{~cm}^{-1}$ [21]. The position $v \approx 2850 \mathrm{~cm}^{-1}$ of the main peak in the absorption band of the $\mathrm{CH}_{0.94}$ sample (bottom panel of Fig. 8) well agrees with the calculations of Refs. $[14,18]$. However, this peak has a rather intense shoulder extending up to $2980 \mathrm{~cm}^{-1}$ that contradicts the calculations. The absorption band of the $\mathrm{CD}_{1.0 .6}$ sample (upper panel of Fig. 9) is even broader. It clearly shows a complex fine structure and its intensity distribution considerably differs from that in the $\mathrm{C}-\mathrm{H}$ band of the $\mathrm{CH}_{0.94}$ sample.

These findings led us to think that the light penetration depth into our samples could be very small, and instead of the light absorption by the regular crystal structure in the bulk of the samples, we only observed results of the light scattering by various defect states on the sample surface.

An accurate analysis of stretching absorption bands of possible surface carbon-hydrogen configurations and their comparison with the deconvoluted bands in the experimental IR spectra of amorphous hydrogenated carbon thin films were carried out in Ref. [33]. The results of that work are presented in columns 1-4 of Table 2. The experiment confirmed the presence of 4 different types of stretching vibrations of $\mathrm{CH}$ groups (bands 1, 2, 4 and 7) and 2 types of vibrations of $\mathrm{CH}_{2}$ groups (bands $6 \mathrm{a}$ and $6 \mathrm{~s}$ ), with coinciding frequency ranges of bands 7 and $6 \mathrm{a}$. One could expect that the surface layers of our samples, which were considerably disturbed by the preliminary ball-milling, reacted with hydrogen similarly to the amorphous films therefore producing the same $\mathrm{C}-\mathrm{H}$ groups vibrating in the same way as in Ref. [33]. 


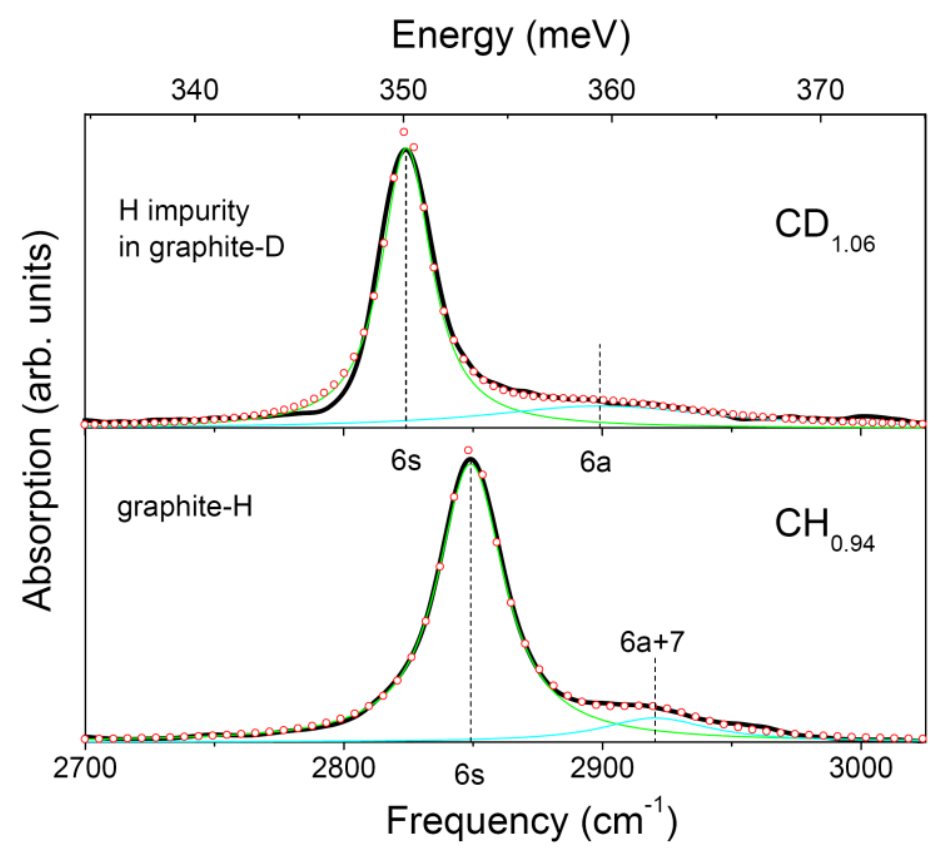

Fig. 8 - IR absorption spectra, $\mathrm{A}(\mathrm{v})$, of $\mathrm{C}-\mathrm{H}$ stretching vibrations in the $\mathrm{CH}_{0.94}$ sample (bottom panel) and $\mathrm{CD}_{1.06}$ sample (top panel, modes due to the $\mathrm{H}$ impurity). Thick solid lines represent the experimental spectra; thin solid lines show a deconvolution of these spectra to Lorentzians; chains of open circles embody the Lorentzians; vertical dashed lines indicate the centers of the Lorentzians. The bands are numbered as in Table 2.

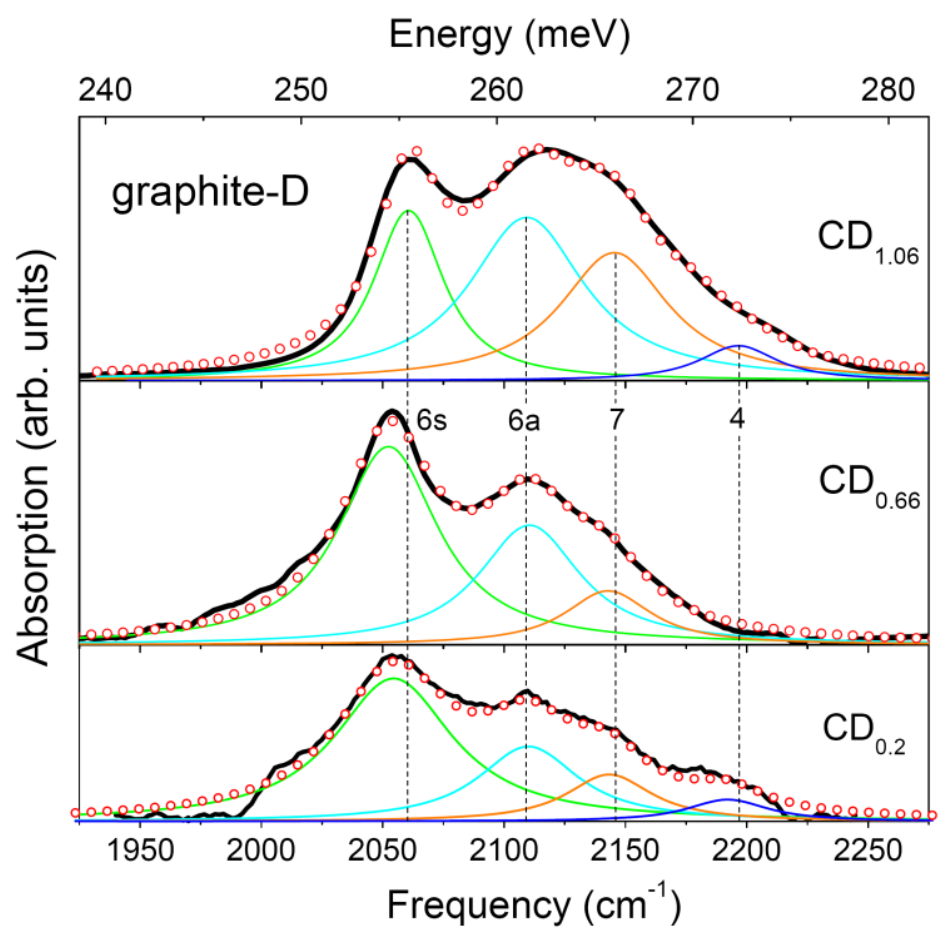

Fig. 9 - IR absorption spectra, A(v), of C-D stretching vibrations in three samples of deuterated graphite with different mean deuterium concentrations resulted from the different proportions between the unreacted graphite and hydrographite with the composition close to CD. The lines have the same meaning as in Fig. 8. The bands are numbered as in Table 2. 
Table 2 - Deconvoluted C-H and C-D stretching absorption bands. Columns 1-4 are from Ref. [33] and present the configuration (2) and predicted (3) and experimental (4) frequencies of $\mathrm{CH}_{\mathrm{n}}$ groups $(\mathrm{n}=1,2,3)$ at the surface of hydrogenated amorphous carbon films. The di- and trihydrogen bands are doublets with a "symmetric" (s) and "antisymmetric" (a) vibration. Frequencies in column 6 are for the deuterium-substituted configurations from column 2 calculated in a harmonic approximation using frequencies from column 3. Columns 5, 7 and 8 show experimental results for the $\mathrm{CH}_{0.94}$ and $\mathrm{CD}_{1.06}$ samples of crystalline hydrographite studied in the present paper. All experimental results are presented in the form "peak frequency/halfwidth" of the corresponding Lorentzian.

\begin{tabular}{llllllll}
\hline $\begin{array}{l}\text { Band } \\
\text { No. } \\
{[33]}\end{array}$ & $\begin{array}{l}\text { Configuration } \\
{[33]}\end{array}$ & $\begin{array}{l}\text { Predicted } \\
\mathrm{C}-\mathrm{H} \text { bands } \\
{[33]\left(\mathrm{cm}^{-1}\right)}\end{array}$ & $\begin{array}{l}\mathrm{C}-\mathrm{H} \text { bands in } \\
\text { amorphous } \\
\text { carbon }[33] \\
\left(\mathrm{cm}^{-1}\right)\end{array}$ & $\begin{array}{l}\mathrm{C}-\mathrm{H} \\
\text { bands in } \\
\mathrm{CH}_{0.94} \\
\left(\mathrm{~cm}^{-1}\right)\end{array}$ & $\begin{array}{l}\text { Predicted } \\
\text { bands } \\
\left(\mathrm{cm}^{-1}\right)\end{array}$ & $\begin{array}{l}\mathrm{C}-\mathrm{D} \\
\text { bands in } \\
\mathrm{CD}_{1.06} \\
\left(\mathrm{~cm}^{-1}\right)\end{array}$ & $\begin{array}{l}\text { C-H impurity } \\
\text { bands in } \\
\mathrm{CD}_{1.06}\left(\mathrm{~cm}^{-1}\right)\end{array}$ \\
\hline 1 & 2 & 3 & 4 & 5 & 6 & 7 & 8 \\
\hline 1 & $\mathrm{sp}^{1} \mathrm{CH}$ & 3305 & $3300 / 44$ & - & 2427 & - & - \\
2 & $\mathrm{sp}^{2} \mathrm{CH}$ (arom.) & 3050 & $3045 / 68$ & - & 2239 & - & - \\
$3 \mathrm{a}$ & $\mathrm{sp}^{2} \mathrm{CH}$ (olef.) & 3020 & - & - & - & - & - \\
4 & $\mathrm{sp}^{2} \mathrm{CH}$ (olef.) & 3000 & $3000 / 78$ & - & 2203 & $\sim 2200 / 27$ & - \\
$5 \mathrm{a}$ & $\mathrm{sp}^{3} \mathrm{CH}_{3}$ (asym.) & 2960 & - & & - & - & - \\
$3 \mathrm{~s}$ & $\mathrm{sp}^{2} \mathrm{CH}_{2}$ (olef.) & 2950 & - & - & - & - & - \\
$6 \mathrm{a}$ & $\mathrm{sp}^{3} \mathrm{CH}_{2}$ (asym.) & 2925 & $2920 / 88$ & $2920 / 25$ & 2110 & $2109 / 27$ & $\sim 2900 / 40$ \\
7 & $\mathrm{sp}^{3} \mathrm{CH}^{2}$ & 2915 & $2920 / 88$ & $2920 / 25$ & 2140 & $2146 / 20$ & $?$ \\
$5 \mathrm{~s}$ & $\mathrm{sp}^{3} \mathrm{CH}_{3}$ (sym.) & 2870 & & & - & - & - \\
$6 \mathrm{~s}$ & $\mathrm{sp}^{3} \mathrm{CH}_{2}$ (sym.) & 2855 & $2850 / 78$ & $2849 / 15$ & 2060 & $2060 / 15$ & $2824 / 8$ \\
\hline
\end{tabular}

A deconvolution of the overlapping absorption bands in our $\mathrm{CH}_{0.94}$ sample into two Lorentzians is depicted in Fig. 8 (bottom panel) by thin lines. The positions and widths of these Lorentzians are indicated in column 5 of Table 2. As one can see, the two deconvoluted bands thus obtained are bands $6 \mathrm{~s}$ and $(6 \mathrm{a}+7)$ predicted in [33] and having the maximum integral intensities in the IR spectra of amorphous hydrogenated carbon films studied experimentally [33].

The band of stretching $\mathrm{C}-\mathrm{D}$ vibrations in the $\mathrm{CD}_{1.0 .6}$ sample can be deconvoluted into 4 Lorentzians (see the upper panel in Fig. 9). To check if the deconvolution is meaningful, we also measured and deconvoluted spectra of two other samples of deuterated graphite, $\mathrm{CD}_{0.66}$ and $\mathrm{CD}_{0.20}$, containing, respectively, about 34 and 80 mol.\% of unreacted graphite. As one can see from Fig. 9, the positions and widths of the Lorentzians are rather well reproduced in all three spectra, the only exception being the Lorentzian at $\sim 2197 \mathrm{~cm}^{-1}$ missing in the spectrum of the $\mathrm{CD}_{0.66}$ sample. 
To assign the obtained frequencies to particular carbon-deuterium configurations, we calculated the frequencies of stretching vibrations of the $\mathrm{CD}$ and $\mathrm{CD}_{2}$ groups in a harmonic approximation by dividing the predicted frequencies for the $\mathrm{CH}$ and $\mathrm{CH}_{2}$ groups (column 3) by a square root of the corresponding ratio of the reduced masses, $\sqrt{\mathrm{M}_{\mathrm{CD}} / \mathrm{M}_{\mathrm{CH}}} \approx 1.362$ or $\sqrt{\mathrm{M}_{\mathrm{CD}_{2}} / \mathrm{M}_{\mathrm{CH}_{2}}} \approx 1.386$. The reduced masses were determined from equations $1 / \mathrm{M}_{\mathrm{CH}}=1 / \mathrm{m}_{\mathrm{C}}+1 / \mathrm{m}_{\mathrm{H}}$ and $1 / \mathrm{M}_{\mathrm{CH}_{2}}=1 / \mathrm{m}_{\mathrm{C}}+2 / \mathrm{m}_{\mathrm{H}}$ and analogues equations for the deuteriumsubstituted groups, using the atomic masses $\mathrm{m}_{\mathrm{C}}, \mathrm{m}_{\mathrm{H}}$ and $\mathrm{m}_{\mathrm{D}}$ of carbon, protium and deuterium.

The calculated frequencies for the $\mathrm{CD}$ and $\mathrm{CD}_{2}$ groups are given in column 6 of Table 2 and allow unequivocal assignments of all four deconvoluted bands of stretching C-D vibrations in the $\mathrm{CD}_{1.06}$ sample (column 7). Note that band 7 lies slightly lower than band 6a in the carbonprotium spectra (column 3), but has a considerably higher frequency than band 6a in the carbondeuterium spectra (column 6). Since the effect is due to the different isotopic dependences of frequencies of stretching vibrations of the $\mathrm{CH}$ and $\mathrm{CH}_{2}$ groups, the agreement between the calculated and experimental frequencies for band 7 additionally confirms that the assignments of the deconvoluted C-D bands (column 7) are correct. The occurrence of band 7 detached from band $6 \mathrm{a}$ in the $\mathrm{C}-\mathrm{D}$ spectra also partly explains the striking difference in the intensity distribution in the $\mathrm{C}-\mathrm{D}$ and $\mathrm{C}-\mathrm{H}$ spectra of the deuterated and hydrogenated graphite.

There is, however, another feature of stretching vibrations in hydrographite that we cannot explain at the moment. As one can see from the bottom panel of Fig. 8, the integral intensity of bands $(6 \mathrm{a}+7)$ located at $2920 \mathrm{~cm}^{-1}$ is much lower than that of band $6 \mathrm{~s}$ at $2850 \mathrm{~cm}^{-1}$. At the same time, the frequencies $\left(v_{6 \mathrm{a}} \approx 2925 \mathrm{~cm}^{-1}\right.$ and $\left.v_{6 \mathrm{~s}} \approx 2855 \mathrm{~cm}^{-1}\right)$ and relative intensities $\left(\mathrm{I}_{6 \mathrm{a}} / \mathrm{I}_{6 \mathrm{~s}} \approx 3 / 1\right)$ of bands $6 \mathrm{a}$ and $6 \mathrm{~s}$ of antisymmetric and symmetric stretching vibrations of methilene groups $\mathrm{CH}_{2}$ are known to experience little changes in nearly all atomic environments (see, e.g., Ref. [34] and references therein). Particularly, experiment gave $\mathrm{I}_{6 \mathrm{a}}>\mathrm{I}_{6 \mathrm{~s}}$ for the amorphous hydrogenated carbon films [33].

So far as the $\mathrm{I}_{6 \mathrm{a}} / \mathrm{I}_{6 \mathrm{~s}}$ ratio is concerned, the samples of hydrogenated graphite considerably differ even from the deuterated samples. In the IR spectra of deuterated graphite shown in Fig. 9, band $6 \mathrm{a}$ has a higher integral intensity than band $6 \mathrm{~s}$ in the single-phase sample $\mathrm{CD}_{1.06}$ and a smaller but comparable intensity in the two-phase samples $\mathrm{CD}_{0.66}$ and $\mathrm{CD}_{0.2}$. The intensity of band 7 of stretching vibrations of the methylylidene CD groups is smaller but comparable with the intensity of band $6 \mathrm{~s}$ in all three C-D samples. In contrast, our nearly single-phase $\mathrm{CH}_{0.94}$ sample has $\mathrm{I}_{(6 \mathrm{a}+7)} / \mathrm{I}_{6 \mathrm{~s}} \approx 1 / 7$ (this result, however, can only be considered as an estimate by the order of magnitude in view of the uncertainty in the smooth "baseline" subtracted from the experimental IR spectrum in order to isolate the $A(v)$ spectrum of stretching vibrations). 
The last thing to be discussed in this Section is the stretching vibrations resulting from the presence of $\mathrm{H}$ impurity in the $\mathrm{CD}_{1.06}$ sample of deuterated graphite. As seen from Fig. 8, the spectrum of these vibrations (top panel) looks similar to the spectrum of stretching vibrations in the isotopically pure $\mathrm{CH}_{0.94}$ sample (bottom panel) shifted by $\approx 25 \mathrm{~cm}^{-1}$ to lower frequencies. Results of deconvolution of the impurity spectrum into two Lorentzians are shown in Fig. 8 by the thin solid lines and presented in the last column of Table 2. The ratio of the integral intensities of the Lorentzians is of the order of $1 / 3$.

Since the $\mathrm{CD}_{1.06}$ sample was synthesized in an atmosphere of the gas with an atomic ratio of $\mathrm{H} / \mathrm{D} \approx 0.03$, it is reasonable to expect that the sample also had $\mathrm{H} / \mathrm{D} \ll<1$. Consequently, the impurity spectrum should mostly be composed of stretching bands of $\mathrm{CH}$ and $\mathrm{CDH}$ groups, because the probability of formation of $\mathrm{CH}_{2}$ groups was smaller than that of the CHD groups approximately by a factor of (H/D). Irrespective of the atomic environment, the bands of stretching vibrations of the CHD group are known to little differ in frequency and relative intensity from the antisymmetric and symmetric stretching bands of the $\mathrm{CH}_{2}$ groups, and only the width of the symmetric band noticeably decreases (see, e.g., Ref. [34] where these features of the CHD vibrations were demonstrated on the example of isotopically isolated $n-\mathrm{C}_{36} \mathrm{H}_{74}$ chains in an $\mathrm{n}-\mathrm{C}_{36} \mathrm{D}_{74}$ crystal). This is exactly as the $\mathrm{H}$ impurity spectrum of the $\mathrm{CD}_{1.06}$ sample looks like, including the narrowing of the $6 \mathrm{~s}$ band. The presence of band 7 of stretching vibrations of the impurity $\mathrm{CH}$ groups in the deuterated sample is also likely, because this would explain the large half-width of the deconvoluted impurity 6 a band $\left(40 \mathrm{~cm}^{-1}\right.$ compared to $25 \mathrm{~cm}^{-1}$ in the $\mathrm{CH}_{0.94}$ sample) and the smaller decrease in its frequency compared to the impurity 6s band (by 20 and $25 \mathrm{~cm}^{-1}$, respectively) relative to the frequencies of bands $6 \mathrm{a}$ and $6 \mathrm{~s}$ in the spectrum of the $\mathrm{CH}_{0.94}$ sample (see Table 2).

\section{Conclusions}

Summarizing the obtained results, the properties of hydrographite can be described as follows:

- Hydrographite is a solid black compound with the composition close to $\mathrm{CH}$. This compound can be synthesised by exposing graphite to an atmosphere of molecular hydrogen at $\mathrm{P}>2 \mathrm{GPa}$ and $450<\mathrm{T}<700^{\circ} \mathrm{C}$. The yield of the reaction increases, if the surface of the graphite is activated by ball milling.

- Hydrographite is thermally stable under ambient conditions. If heated in vacuum, it decomposes to graphite and $\mathrm{H}_{2}$ gas in the temperature interval from approx. 500 to $650^{\circ} \mathrm{C}$. Heating above $720-750^{\circ} \mathrm{C}$ in an $\mathrm{H}_{2}$ gas compressed to $7.5 \mathrm{GPa}$ transforms hydrographite to methane and/or other light hydrocarbons. 
- Hydrographite has a hexagonal crystal structure with the lattice parameters a = 2.53(1) $\AA$ and c $=9.54(1) \AA$ and the volume $\mathrm{V}=\frac{\sqrt{3}}{2} \mathrm{a}^{2} \mathrm{c}=52.9(4) \AA^{3} /$ atom $\mathrm{C}$. These values are larger than those of graphite by, respectively, 2.4(2) and 42.0(3) and 49(2)\%.

- Comparison of the X-ray diffraction results with the available ab initio calculations suggests that hydrographite should be a 3D counterpart of graphane. Of the two most stable polytypes predicted for multilayer graphane [18], only the "graphane II" structure is compatible with experiment. This structure belongs to the $\mathrm{P}_{3} \mathrm{mc}$ space group and consists of one-layer sheets of graphane in the chair conformation stacked along the $\mathrm{c}$ axis in the $-\mathrm{ABAB}-$ sequence.

- Infrared spectroscopy revealed an anomalously small ratio of integral intensities of the bands of antisymmetric and symmetric stretching vibrations of $\mathrm{CH}_{2}$ groups on the surface of hydrographite particles. This distinguishes hydrographite from other hydrocarbons.

\section{Acknowledegments}

The work was supported by Grant No. 11-02-00401 from the Russian Foundation for Basic Research and by the Program "The Matter under High Pressure" of the Russian Academy of Sciences. A.I.K. greatly acknowledges the support from the Scientific User Facilities Division, Office of Basic Energy Sciences, US Department of Energy. 


\section{REFERENCES}

[1] Scott HP, Hemley RJ, Mao HK, Herschbach DR, Fried LE, Howard WM, Bastea S. Generation of methane in the Earth's mantle: In situ high pressure-temperature measurements of carbonate reduction. Proc Nat Acad Sci USA 2004;101(39):14023-6.

[2] Kutcherov VG, Kolesnikov AYu, Dyuzheva TI, Kulikova LF, Nikolaev NN, Sazanova OA, Braghkin VV. Synthesis of complex hydrocarbon systems at temperatures and pressures corresponding to the Earth's upper mantle conditions. Dokl Phys Chem 2010;433(1):132-5.

[3] Kutcherov V, Kolesnikov A, Dyuzheva T, Brazhkin V. Synthesis of hydrocarbons under upper mantle conditions: Evidence for theory of abiotic deep petroleum origin. J. Phys.: Conf. Ser. 2010;215:012103 (1-8).

[4] Bashkin IO, Antonov VE, Bazhenov AV, Bdikin IK, Borisenko DN, Krinichnaya EP, et al. Thermally stable hydrogen compounds obtained under high pressure on the basis of carbon nanotubes and nanofibers. JETP Letters 2004;79(5):226-30.

[5] Dillon AC, Heben MJ. Hydrogen storage using carbon adsorbents: past, present and future. Appl Phys A 2001;72(2):133-42.

[6] Orimo S, Majer G, Fukunaga T, Züttel A, Schlapbach L, Fujii H. Hydrogen in the mechanically prepared nanostructured graphite. Appl Phys Lett 1999;75(20):3093-5.

[7] Bashkin IO, Antonov VE, Bazhenov AV, Fursova TN, Lukashev RV, Sakharov M.K, et al. High-pressure hydrogenation of graphite. Extended abstracts, $\mathrm{X}$ internat. conf. "Hydrogen Materials Science and Chemistry of Carbon Nanomaterials” ICHMS'2007. Sudak (Ukraine), 2007; p. 686-7.

[8] Novoselov KS, Geim AK, Morozov SV, Jiang D, Zhang Y, Dubonos SV, et al. Electric field effect in atomically thin carbon films. Science 2004;306:666-9.

[9] Geim AK, Novoselov KS. The rise of graphene. Nature Mater 2007;6:183-91.

[10] Sluiter MHF, Kawazoe Y. Cluster expansion method for adsorption: Application to hydrogen chemisorption on graphene. Phys Rev B 2003;68:085410(1-7).

[11] Sofo JO, Chaudhari AS, Barber GD. Graphane: A two-dimensional hydrocarbon. Phys Rev B 2007;75:153401(1-4).

[12] Elias DC, Nair RR, Mohiuddin TMG, Morozov SV, Blake P, Halsall MP, et al. Control of graphene's properties by reversible hydrogenation: Evidence for graphane. Science 2009;323:610-3.

[13] Artyukhov VI, Chernozatonskii LA. Structure and layer interaction in carbon monofluoride and graphane: A comparative computational study. J Phys Chem A 2010;114(16):5389-96. 
[14] Cadelano E, Palla PL, Giordano S, Colombo L. Elastic properties of hydrogenated graphene. Phys Rev B 2010;82;235414(1-8).

[15] Savini G, Ferrari AC, Giustino F, First-principles prediction of doped graphane as a hightemperature electron-phonon superconductor. Phys Rev Lett 2010;105:037002(1-4).

[16] Dzhurakhalov AA, Peeters FM. Structure and energetics of hydrogen chemisorbed on a single graphene layer to produce graphane. Carbon 2011;49(10):3258-66.

[17] Samarakoon DK, Wang X-Q. Chair and twist-boat membranes in hydrogenated graphene. ACS Nano 2009;3(12):4017-22.

[18] Wen X-D, Hand L, Labet V, Yang T, Hoffmann R, Ashcroft NW, et al. Graphane sheets and crystals under pressure. Proc Nat Acad Sci USA 2011;108(17):6833-7.

[19] Rohrer J, Hyldgaard P. Stacking and band structure of van derWaals bonded graphane multilayers. Phys Rev B 2011;83:165423(1-10).

[20] Leenaerts O, Peelaers H, Hernández-Nieves AD, Partoens B, Peeters FM. First-principles investigation of graphene fluoride and graphane. Phys Rev B 2010;82:195436(1-6).

[21] Peelaers H, Hernández-Nieves AD, Leenaerts O, Partoens B, Peeters FM. Vibrational properties of graphene fluoride and graphane. Appl Phys Lett 2011;98:051914(1-3).

[22] Boukhvalov DW, Katsnelson MI, Lichtenstein AI. Hydrogen on graphene: Electronic structure, total energy, structural distortions and magnetism from first-principles calculations. Phys Rev B 2008;77:035427(1-7).

[23] Antonov VE, Bashkin IO, Khasanov SS, Moravsky AP, Morozov YuG, Shulga YuM, et al. Magnetic ordering in hydrofullerite $\mathrm{C}_{60} \mathrm{H}_{24}$. J Alloys Comp 2002;330-332:365-8.

[24] Khvostantsev LG, Slesarev VN, Brazhkin VV. Toroid type high-pressure device: history and prospects. High Pressure Res 2004;24:371-83.

[25] Antonov VE, Davydov AI, Fedotov VK, Ivanov AS, Kolesnikov AI, Kuzovnikov MA. Neutron spectroscopy of $\mathrm{H}$ impurities in PdD: Covibrations of the $\mathrm{H}$ and $\mathrm{D}$ atoms. Phys Rev B 2009;80(13):134302(1-7).

[26] Kolesnikov AI, Bashkin IO, Antonov VE, Colognesi D, Mayers J, Moravsky AP. Neutron spectroscopy study of single-walled carbon nanotubes hydrogenated under high pressure. J Alloys Comp 2007;446-447:389-92.

[27] Shul'ga YuM, Bashkin IO, Krestinin AV, Martynenko VM, Zvereva GI, Kondrat'eva IV, et al. Spectrum of gases liberated upon the stepwise heating of single-walled carbon nanotubes deuterated under pressure. JETP Letters 2004;80(12):752-6.

[28] Orimo S, Matsushima T, Fujii H, Fukunaga T, Majer G. Hydrogen desorption property of mechanically prepared nanostructured graphite. J Appl Phys 2001;90(3):1545-9. 
[29] Fukunaga T, Nagano K, Mizutani U, Wakayama H, Fukushima Y. Structural change of graphite subjected to mechanical milling. J Non-Cryst Solids 1998;232-234:416-20.

[30] Chen Y, Gerald JF, Chadderton LT, Chaffron L. Nanoporous carbon produced by ball milling. Appl Phys Lett 1999;74(19):2782-4.

[31] Friedel RA, Carlson GL. Infrared spectra of ground graphite. J. Phys Chem 1971;75(8):1149-51.

[32] Born M, Wolf E. Principles of optics. 4th ed. Oxford: Pergamon; 1968.

[33] Dischler B, Bubenzer A, Koidl P. Bonding in hydrogenated hard carbon studied by optical spectroscopy. Solid State Commun 1983;48(2):105-8.

[34] Snyder RG, Hsu SL, Krimm S. Vibrational spectra in the C-H stretching region and the structure of the polymethylene chain. Spectrochimica Acta 1978;34A:395-406. 
Table 1 - Structural parameters of the graphite-D sample with $\mathrm{D} / \mathrm{C}=$ $1.06(5)$ and of pure graphite produced by outgassing this graphite-D sample at $600^{\circ} \mathrm{C}$ in vacuum. The parameters are obtained by a profile analysis of the X-ray diffraction patterns of these samples presented in Fig. 3. Positions of the D atoms could not be reliably determined from experiment and these atoms are placed at a distance of $0.12 \mathrm{c} \approx$ $1.1 \AA$ in the c-direction from the nearest $\mathrm{C}$ atom in accordance with results of most $a b$ initio calculations for the chair conformation of graphane.

\begin{tabular}{|c|c|c|c|}
\hline Sample & graphite (outgassed) & \multicolumn{2}{|c|}{ graphite-D } \\
\hline $\mathrm{D} / \mathrm{C}$ atomic ratio & 0 & \multicolumn{2}{|l|}{$1.06(5)$} \\
\hline Space group & $\mathrm{P}_{3} / \mathrm{mmc}(\mathrm{No} .194)$ & \multicolumn{2}{|c|}{$\mathrm{P}_{3} \mathrm{mc}(\mathrm{No} .186)$} \\
\hline $\begin{array}{l}\text { Positions } \\
\text { of } \mathrm{C} \text { atoms }\end{array}$ & $2 \mathrm{c}(1 / 3,2 / 3,1 / 4)$ & \multicolumn{2}{|c|}{$\begin{array}{l}2 \mathrm{a}(0,0,0) \\
2 \mathrm{~b}(1 / 3,2 / 3,0.05)\end{array}$} \\
\hline $\begin{array}{l}\text { Tentative positions } \\
\text { of } D \text { atoms }\end{array}$ & & \multicolumn{2}{|c|}{$\begin{array}{l}2 \mathrm{a}(0,0,0.88) \\
2 \mathrm{~b}(1 / 3,2 / 3,0.17)\end{array}$} \\
\hline & & & Increase $(\%)$ \\
\hline $\mathrm{a}(\AA)$ & $2.47(1)$ & $2.53(1)$ & $2.4(2)$ \\
\hline$c(\AA)$ & $6.72(1)$ & $9.54(1)$ & $42.0(3)$ \\
\hline $\mathrm{c} / \mathrm{a}$ & $2.72(1)$ & $3.77(2)$ & $39(1)$ \\
\hline$V\left(\AA^{3} /\right.$ atom $\left.C\right)$ & $35.5(3)$ & $52.9(4)$ & $49(2)$ \\
\hline
\end{tabular}


Table 2 - Deconvoluted C-H and C-D stretching absorption bands. Columns 1-4 are from Ref. [32] and present the configuration (2) and predicted (3) and experimental (4) frequencies of $\mathrm{CH}_{\mathrm{n}}$ groups $(\mathrm{n}=1,2,3)$ at the surface of hydrogenated amorphous carbon films. The di- and trihydrogen bands are doublets with a "symmetric" (s) and "antisymmetric" (a) vibration. Frequencies in column 6 are for the deuterium-substituted configurations from column 2 calculated in a harmonic approximation using frequencies from column 3. Columns 5, 7 and 8 show experimental results for the $\mathrm{CH}_{0.94}$ and $\mathrm{CD}_{1.06}$ samples of crystalline hydrographite studied in the present paper. All experimental results are presented in the form "peak frequency/halfwidth" of the corresponding Lorentzian.

\begin{tabular}{|c|c|c|c|c|c|c|c|}
\hline $\begin{array}{l}\text { Band } \\
\text { No. } \\
{[32]}\end{array}$ & $\begin{array}{l}\text { Configuration } \\
\text { [32] }\end{array}$ & $\begin{array}{l}\text { Predicted } \\
\text { C-H bands } \\
{[32]\left(\mathrm{cm}^{-1}\right)}\end{array}$ & $\begin{array}{l}\mathrm{C}-\mathrm{H} \text { bands in } \\
\text { amorphous } \\
\text { carbon [32] } \\
\left(\mathrm{cm}^{-1}\right)\end{array}$ & $\begin{array}{l}\mathrm{C}-\mathrm{H} \\
\text { bands in } \\
\mathrm{CH}_{0.94} \\
\left(\mathrm{~cm}^{-1}\right)\end{array}$ & $\begin{array}{l}\text { Predicted } \\
\text { C-D } \\
\text { bands } \\
\left(\mathrm{cm}^{-1}\right)\end{array}$ & $\begin{array}{l}\mathrm{C}-\mathrm{D} \\
\text { bands in } \\
\mathrm{CD}_{1.06} \\
\left(\mathrm{~cm}^{-1}\right)\end{array}$ & $\begin{array}{l}\text { C-H impurity } \\
\text { bands in } \\
\mathrm{CD}_{1.06}\left(\mathrm{~cm}^{-1}\right)\end{array}$ \\
\hline 1 & 2 & 3 & 4 & 5 & 6 & 7 & 8 \\
\hline 1 & $\mathrm{sp}^{1} \mathrm{CH}$ & 3305 & $3300 / 44$ & - & 2427 & - & - \\
\hline 2 & $\mathrm{sp}^{2} \mathrm{CH}$ (arom.) & 3050 & $3045 / 68$ & - & 2239 & - & - \\
\hline $3 a$ & $\mathrm{sp}^{2} \mathrm{CH}_{2}$ (olef.) & 3020 & - & - & - & - & - \\
\hline 4 & $\mathrm{sp}^{2} \mathrm{CH}$ (olef.) & 3000 & $3000 / 78$ & - & 2203 & $\sim 2200 / 27$ & - \\
\hline $5 a$ & $\mathrm{sp}^{3} \mathrm{CH}_{3}$ (asym.) & 2960 & - & & - & - & - \\
\hline $3 \mathrm{~s}$ & $\mathrm{sp}^{2} \mathrm{CH}_{2}$ (olef.) & 2950 & - & - & - & - & - \\
\hline $6 a$ & $\mathrm{sp}^{3} \mathrm{CH}_{2}$ (asym.) & 2925 & $2920 / 88$ & $2920 / 25$ & 2110 & $2109 / 27$ & $\sim 2900 / 40$ \\
\hline 7 & $\mathrm{sp}^{3} \mathrm{CH}$ & 2915 & $2920 / 88$ & $2920 / 25$ & 2140 & $2146 / 20$ & $?$ \\
\hline $5 \mathrm{~s}$ & $\mathrm{sp}^{3} \mathrm{CH}_{3}(\mathrm{sym})$. & 2870 & & & - & - & - \\
\hline $6 s$ & $\mathrm{sp}^{3} \mathrm{CH}_{2}$ (sym.) & 2855 & $2850 / 78$ & $2849 / 15$ & 2060 & $2060 / 15$ & $2824 / 8$ \\
\hline
\end{tabular}

